\title{
Comparative Study between Alvarado Score\& Ripasa Score in Diagnosis of Acute Appendicitis
}

Mostafa M. Elhosseiny ${ }^{1 *}$, Eman Eltokhy ${ }^{1}$, Omar Atef Elekiabi ${ }^{1}$, Mostafa M. Elaidy ${ }^{1}$, Tamer Mohamed El shahidy ${ }^{1}$, Amir M. Salem ${ }^{2}$, Ahmed Embaby ${ }^{3}$

Keywords: a cute appendicitis; Alvarado Score; RIPASA Score

\section{Abstract}

Background: Acute appendicitis is one of commonest surgica emergencies, and it is more prevalent in the second and third decades and decreasing with age. Up-till now there are no laboratory parameters that could indicate reliable for diagnosis of acute appendicitis. Several diagnostic scores have been developed to increase the diagnostic accuracy in acute appendicitis. Many studies in the literature are available on diagnostic scores for acute appendicitis as Alvarado Score \& RIPASA Score.

Aim of work: Evaluation and comparison of Alvarado score and RIPASA score in diagnosis of a cute appendic itis to state which is more convenient in diagnosis of a cute appendic itis.

Patient and methods: This study was conducted on 56 patients with suspected acute a ppend ic itis in emergency surgic al department. Comparing between Alvarado, RIPASA scoring systems and histopathology of appendix of the same patient was done.

Results: Statistic al a nalysis of the data revealed that RIPASA score is superior in diagnosis of a cute appendic itis with sensitivity $100 \%$ and with accuracy $88 \%$, and negative predic tive value $100 \%$ and negative appendectomy rate $4.1 \%$. But ALVARADO score is better in exclusion of acute appendicitis diagnosis with high specificity $100 \%$ and positive predictive value $100 \%$ and negative appendectomy rate zero percentage.

Conclusion: ALVARADO is sensitive in the diagnosis of acute appendic itis.

\section{Introduction}

Acute appendicitis is one of commonest surgical emergencies, and it is more prevalent in the second and third decades and decreasing with age [1]. Appendicitis should be considered in the differential diagnosis of almost every patient with acute abdominal pain. The typical presentation begins with peri-umblical pain, followed by anorexia and nausea. The pain localizes to the right lower quadrant as the inflammatory process progresses to involve the parietal peritoneum overlying the appendix. This classic pattern of migratory pain is the most reliable symptom of acute appendicitis [2].

Up till now there are no laboratory parameters that could indicate reliable for diagnosis of acute appendicitis. Ultrasonography has a sensitivity of approximately $85 \%$ and specificity about $90 \%$ in diagnosis [3].

With the use of CT the number of negative appendectomy has been decreased recently [4].

There has been a need of scoring system with acceptable sensitivity, specificity and negative appendectomy rate [5].

Several diagnostic scores have been developed to increase the diagnostic accuracy in acute appendicitis. Many studies in the literature are available on diagnostic scores for acute appendicitis as

\section{Journal of} Surgery
${ }^{1}$ Department of General surgery, Zagazig University, Egypt

${ }^{2}$ Department of Pathology, Zagazig University, Egypt

${ }^{3}$ Department of Internal Medicine, Zagazig University, Egypt

\section{*Address for Correspondence}

Elhosseiny MM, Department of General surgery, Faculty of Medicine, Zagazig University, Egypt, E-mail: mostafaelhosseiny@gmail.com

Submission: 07 September, 2018

Accepted: 03 October, 2018

Published: 10 October, 2018

Copyright: (c) 2018 Elhosseiny MM. This is an open access article distributed under the Creative Commons Attribution License, which permits unrestricted use, distribution, and reproduction in any medium, provided the original work is properly cited.

Alvarado Score, RIPASA Score, Tzanakis Score, Lintula score and many other scores $[6,7]$.

\section{Aim of work}

Evaluation and comparison of Alvarado score and Ripasa score in diagnosis of acute appendicitis to state which is more convenient in diagnosis of acute appendicitis.

\section{Patient and Methods}

This study was conducted on 56 patients in General Surgery Department, Faculty of Medicine, Zagazig University Hospitals at emergency unit, and Pathology Department, Faculty of Medicine, Zagazig University over a period of six months from February 2017 to August 2017 after approval by the local ethical committee. And a written informed consent was received from the included patients.

\section{Population or subjects}

Patients suspected acute appendicitis in emergency surgical department.

\section{Study design}

Cross - Sectional study will be used in carrying out this study.

\section{Data collection tools}

Clinical examination: by the following: Demographic data including name, age, gender, residence, occupation, marital status, special habits of medical importance and menstrual history for females.

Analysis of the main complaint which is pain in the right iliac fossa. A detailed present history was taken regarding the onset, duration and course of symptoms.

Past history of previous operations, chronic diseases (e.g. cardiac diseases, Diabetes Mellitus, liver disease), drug allergy\& intake and blood transfusion.

Clinical examination including, general examination for vital signs and other systems to assess fitness for surgery and anesthesia. 
Citation: Mostafa M. Elhosseiny, Eman Eltokhy, Omar Atef Elekiabi, Mostafa M. Elaidy, Tamer Mohamed El shahidy, et al. Comparative Study between Alvarado Score\& Ripasa Score in Diagnosis of Acute Appendicitis. J Surgery. 2018;6(2): 5.

ISSN: $2332-4139$

Table 1: Patients clinical data at time of presentation.

\begin{tabular}{|c|c|c|c|}
\hline & & Frequency & Percent \\
\hline \multirow{2}{*}{ Gender } & Male & 20 & 35.7 \\
\hline & Female & 36 & 64.3 \\
\hline \multirow{2}{*}{ Age, years } & Mean \pm SD & \multicolumn{2}{|c|}{$28.3 \pm 8.1$} \\
\hline & Median (Range) & \multicolumn{2}{|c|}{$25(21-45)$} \\
\hline \multicolumn{2}{|c|}{ RIF pain } & 56 & 100 \\
\hline \multicolumn{2}{|c|}{ Pain migration to RIF } & 56 & 100 \\
\hline \multicolumn{2}{|c|}{ Fever } & 30 & 53.6 \\
\hline \multicolumn{2}{|c|}{ Anorexia } & 25 & 44.6 \\
\hline \multicolumn{2}{|c|}{ Nausea \& vomiting } & 26 & 46.4 \\
\hline \multirow{5}{*}{ Duration of symptoms, days } & \multicolumn{3}{|c|}{$<48$ hours } \\
\hline & $1 \mathrm{D}$ & 8 & 14.3 \\
\hline & $2 \mathrm{D}$ & 10 & 17.9 \\
\hline & \multicolumn{3}{|c|}{$\geq 48$ hours } \\
\hline & $3 \mathrm{D}$ & 27 & 48.2 \\
\hline \multicolumn{2}{|c|}{ RIF tenderness } & 56 & 100 \\
\hline \multicolumn{2}{|c|}{ Guarding } & 18 & 32.1 \\
\hline \multicolumn{2}{|c|}{ Rebound tenderness } & 50 & 89.3 \\
\hline \multicolumn{2}{|c|}{ Rovsing sign } & 40 & 71.4 \\
\hline \multicolumn{2}{|c|}{ Raised WBCs } & 48 & 85.7 \\
\hline \multicolumn{2}{|c|}{ Increase neutrophils } & 10 & 17.9 \\
\hline \multicolumn{2}{|c|}{ Negative urine analysis } & 44 & 78.6 \\
\hline
\end{tabular}

Local examination (abdominal examination) is done focusing on the site of pain (right iliac fossa tenderness with or without guarding).

Signs of acute appendicitis(right iliac fossa pain,tenderness rebound tenderness, positive rovsing sign, fever ).

Laboratory investigations; $\mathrm{CB}$, urine.

Ultrasonography of abdomen and pelvis.

Histopathology of appendix after appendectomy.

\section{Inclusion criteria}

Patients suspected acute appendicitis in emergency department.

Aged between 15-60 years old.

\section{Exclusion criteria}

Patients with right loin pain referred to groin as renal pain, history of urolithiasis.

History of pelvic inflammatory disease.

Pregnant females.

Patients with generalized peritonitis.

Complicated appendicitis (appendicular mass, appendicular abscess).

Diabetic and Immunocompromized patient.

Inability to follow up in hospital.

Neurological deficits interfere with the ability to localize abdominal pain.

Hypotension.

Patient did not undergo surgery.

\section{Operational design}

Type of the study: Cross - Sectional study.

\section{Steps of performance}

Patient with acute abdominal pain with inclusion and exclusion criteria.

Clinical examination and laboratory investigation; $\mathrm{CBC}$ and urine analysis of the selected patient.

All the patients were scored as Alvarado and RIPASA scoring systems. RIPASA and Alvarado score will be only done for the study purpose.

U.S Abdomen, pelvis.

Histopathology of appendix after appendectomy.

\section{Follow up}

Patients were monitored following admission, surgery and till discharge from the hospital.

Comparing between Alvarado, RIPASA scoring systems and histopathology of appendix of the same patient was done.

The patients who were treated conservatively in hospital then discharged home were contacted and followed up.

The cases which were on medical treatment at home and signs and symptoms relieved in the first two weeks after discharge were considered negative cases.

\section{Statistical analysis}

The collected data were tabulated and statistically analyzed using SPSS program (Statistical Package for Social Science) version 24.

Qualitative data were represented as frequencies and relative 
Citation: Mostafa M. Elhosseiny, Eman Eltokhy, Omar Atef Elekiabi, Mostafa M. Elaidy, Tamer Mohamed El shahidy, et al. Comparative Study between Alvarado Score\& Ripasa Score in Diagnosis of Acute Appendicitis. J Surgery. 2018;6(2): 5.

ISSN: 2332-4139

Table 2: Qualitative analysis of both the RIPASA \& Alvarado scoring systems.

\begin{tabular}{|c|c|c|c|c|}
\hline \multicolumn{2}{|c|}{} & \multicolumn{2}{c|}{ RIPASA Score } & \multirow{2}{*}{ Total } \\
\cline { 2 - 5 } & $<7.5$ & $\geq 7.5$ & \\
\hline \multirow{2}{*}{ Alvarado Score } & $\geq 7$ & $0(0.0 \%)$ & $30(62.5 \%)$ & $30(53.6 \%)$ \\
\cline { 2 - 5 } & $<7$ & $8(100.0 \%)$ & $18(37.5 \%)$ & $26(46.4 \%)$ \\
\hline \multicolumn{2}{|c|}{ Total } & $8(100.0 \%)$ & $48(100.0 \%)$ & $56(100.0 \%)$ \\
\hline
\end{tabular}

Table 3: Frequency of Histopathological findings.

\begin{tabular}{|c|c|c|c|c|c|}
\hline & $\begin{array}{c}\text { No. of } \\
\text { patients }\end{array}$ & Frequency & Percent & $\begin{array}{c}\text { Alvarado } \\
\text { Score } \\
\text { Mean } \pm \text { SD }\end{array}$ & $\begin{array}{c}\text { RIPASA } \\
\text { Score }\end{array}$ \\
\hline Mean \pm SD \\
\hline Appendicitis & 46 & 46 & 82.1 & $7.7 \pm 1.8$ & $11.3 \pm 2.7$ \\
\hline $\begin{array}{c}\text { Normal } \\
\text { appendix }\end{array}$ & 8 & 8 & 14.3 & $4.3 \pm 0.5$ & $6.1 \pm 1.5$ \\
\hline Conservative & 2 & 2 & 3.6 & $3 \pm 0$ & $3.5 \pm 0.7$ \\
\hline
\end{tabular}

Table 4: Comparison of Alvarado scoring diagnosis with histopathological diagnosis.

\begin{tabular}{|c|c|c|c|}
\hline & \multicolumn{2}{|c|}{ Histopathology } & \multirow{2}{*}{$\begin{array}{l}\text { Total } \\
\mathrm{N}=54\end{array}$} \\
\hline & $\begin{array}{l}\text { Appendicitis } \\
N=46\end{array}$ & $\begin{array}{l}\text { No Appendicitis } \\
\qquad N=8\end{array}$ & \\
\hline \multicolumn{4}{|c|}{ Alvarado score } \\
\hline$<7$ & 16 & 8 & 24 \\
\hline$\geq 7$ & 30 & 0 & 30 \\
\hline Total & 46 & 8 & 54 \\
\hline \multicolumn{4}{|c|}{ RIPASA Score } \\
\hline$<7.5$ & 0 & 6 & 6 \\
\hline$\geq 7.5$ & 46 & 2 & 48 \\
\hline Total & 46 & 8 & 54 \\
\hline
\end{tabular}

percentages.

Chi square test $\left(\chi^{2}\right)$ and Fisher exact was used to calculate difference between qualitative variables as indicated.

Quantitative data were expressed as mean \pm SD (Standard deviation) for parametric and median and range for non-parametric data.

The significance level for all above mentioned statistical tests was done $\mathrm{P}$-value $\leq 0.05$ indicates significant, $\mathrm{p}<0.001$ indicates highly significant difference while, $\mathrm{P}>0.05$ indicates non-significant difference.

\section{Results}

This study included 56 patients that were divided into 36 female and 20 male with mean age 28.3 years old as shown in (Table 1 ).

The most frequent complaint was pain shift to right iliac fossa followed by fever the least complain was anorexia. The frequency of clinical findings in the study patients presented in (Table 1).

Statistical analysis of the presenting symptoms revealed that the presence of right iliac fossa pain and increased duration of symptoms is highly significant in diagnosis of acute appendicitis in relation to nausea and vomiting (Table 1).

The most frequent clinical sign was tender Mc Burney's point followed by rebound tenderness and Rovsing sign (Table 1).

Laboratory results among the study patients, namely white blood count, neutrophilia and negative urine analysis presented in (Table $1)$.

Statistical analysis of the lab findings revealed that the presence of increased white blood cells sign is highly significant in diagnosis of acute appendicitis in relation to neutrophis and negative urine analysis (Table 1).

The ALVARADO and RIPASA scores were calculated for all patients of the study, ALVARADO score suspected appendicitis in (30) patients and RIPASA score suspected appendicitis in (48) patients (Table 2).

Throughout the study appendectomy performed in (54) patients, and conservative measures offered in (2) patients. The appendectomy specimen underwent histopathologic examination and the results presented in (Table 3).

ALVARADO score denied the susceptibility of appendicitis in (24) patients and confirmed its existence in (30) patients after hisopathologic examination of the removed appendix all the specimen's suspected as appendicitis by ALVARADO score were confirmed by histopathology, and among the denied (24) patients (16) proved to have appendicitis by histopathology (Table 3 ).

RIPASA score denied the susceptibility of appendicitis in (6) patients and confirmed its existence in (48) patients after hisopathologic examination of the removed appendix all the specimen's suspected as appendicitis by RIPASA score were confirmed by histopathology, and among the denied (8) patients (46) proved to have appendicitis by histopathology (Table 3).

Statistical analysis of the data revealed that RIPASA score is superior in diagnosis of acute appendicitis with sensitivity $100 \%$ and with accuracy $88 \%$, and negative predictive value $100 \%$ and negative appendectomy rate $4.1 \%$. But ALVARADO score is better in exclusion of acute appendicitis diagnosis with high specificity $100 \%$ and positive predictive value $100 \%$ and negative appendectomy rate zero percentage. As explained in (Table 4).

Throughout the study we have got a result of positive appendicitis using RIPASA scoring in (48) cases two of them were negative for acute appendicitis after histopathology, and (30) cases of acute appendicitis using ALVARADO score all of them were positive for acute appendicitis after histopathologic examination thus negative appendectomy rate was $4.17 \%$ in RIPASA score and zero percent in ALVARADO score (Tables 3-5)

Table 5: Comparison of Alvarado with RIPASA scoring in the diagnosis of acute appendicitis.

\begin{tabular}{|c|c|c|}
\hline & Alvarado score & RIPASA score \\
\hline Sensitivity & $65.22 \%$ & $100.00 \%$ \\
\hline Specificity & $100.00 \%$ & $75.00 \%$ \\
\hline Accuracy & $83 \%$ & $88 \%$ \\
\hline Disease prevalence & $85.19 \%$ & $85.19 \%$ \\
\hline Positive Predictive Value & $100.00 \%$ & $95.83 \%$ \\
\hline Negative Predictive Value & $33.33 \%$ & $100.00 \%$ \\
\hline Negative appendectomy rate & $0.00 \%$ & $4.17 \%$ \\
\hline
\end{tabular}


Citation: Mostafa M. Elhosseiny, Eman Eltokhy, Omar Atef Elekiabi, Mostafa M. Elaidy, Tamer Mohamed El shahidy, et al. Comparative Study between Alvarado Score\& Ripasa Score in Diagnosis of Acute Appendicitis. J Surgery. 2018;6(2): 5.

ISSN: 2332-4139

\section{Discussion}

Appendicitis is the most common acute abdominal surgical emergency. Appendectomy is the most frequently performed urgent abdominal operation. Delay in the treatment of acute appendicitis causes a lot of complications. Early diagnosis remains the most important clinical goal in patient with suspected appendicitis. The implication of Alvarado and RIPASA scores help in diagnosis or exclusion of the presence of acute appendicitis, thus decreasing the unnecessary admission and rate of negative appendectomy.

In our study there were 56 cases included, appendicitis is more common in females (36 cases) than males (20 cases). This supported by Khan, et al. [8], and Owen TD, et al. [9] with more prevalence of acute appendicitis in male.

In study of Sand, et al. [10] to detect the epidemiology of acute appendicitis among 971 cases, they found that the incidence in males was 1.33 per thousand versus 0.99 for females. There was statistically significant $(\mathrm{p}=0.0002)$. The mean yearly incidences of appendectomies were 1.72 per thousand for males and 1.71 for females. There was a difference from our study about prevalence among sex this supported also by study of Yih, et al. [11].

According to distribution of acute appendicitis among age groups in our study, the mean was (28.3 \pm 8.1$)$ and median was (25 (21-45)). This was supported by Lee and Hog [12] as the acute appendicitis more common in adolescence stage. This also supported by Hawkins \& Thirlby [13].

Of all the symptoms, anorexia and fever came out to be statistically significant (with p value 0.001 and 0.005 right iliac pain, and duration of symptoms came out to be highly significant (with $\mathrm{p}$ value $>0.001$ and $<0.001$, respectively). Regarding the presenting symptoms frequency we found right iliac fossa pain in all patients as it is the principle inclusion criterion in our study followed by fever in $55.6 \%$, pain shift in $51.9 \%$ nausea and vomiting in $48.1 \%$ and lastly anorexia in $46.3 \%$. This agrees with the study of Prashant, et al. [14] \& Singla, et al. [15], regarding the frequency of nausea, vomiting and anorexia but not fever.

We found the most presenting signs were tender right iliac fossa and rebound tenderness, positive Rovsing's sign. with $\mathrm{P}$ value of the last $2,<0.001$ highly significant and $\mathrm{P}$ value of gardening 0.041 , significant, these findings coincident with the findings of Regar, et al. [16].

Our laboratory results found raised white blood count highly significant, and negative urine analysis significant, with $\mathrm{P}$ value $<0.001$ and 0.031 respectively and this agrees with Singh, et al. [15].

Alvarado score when applied in all the clinically suspected patients, has 30 cases (53.6\%) with score $>7$ and 26 Cases (46.4\%) with score less than 7 . When analyzed with respect to histopathology the sensitivity of the scoring system in the present study came out to be $65 \%$, specificity was $100 \%$, positive and negative predictive values were $100 \%$, and $33.33 \%$, respectively. Accuracy was $83 \%$, and no Negative appendectomy rate.

Dey, et al. [17] study reported the sensitivity and specificity of Alvarado score to be $94.2 \%$ and $70 \%$ respectively, positive and negative predictive values of Alvarado score were $86.9 \%$ and $69.80 \%$. Negative appendectomy rate in that study was $13 \%$. The sensitivity in the present study was $65 \%$, which is around $29 \%$ less than quoted study, specificity being $30 \%$ higher in present study which is nearly comparable with the quoted study.

It can be concluded from studies by Jawaid, et al. [18], Baiday N, et al. [19], Chan MY, et al. [20], Khan, et al. [8] \& Regar, et al. [16] that sensitivity, specificity, positive predictive value and negative predictive value of Alvarado scoring system range from $59 \%$ to $89 \%$, $23 \%$ to $70 \%, 77 \%$ to $98 \%$ and $69.8 \%$ to $98 \%$ respectively.

RIPASA score when applied in all patients suspected to be acute appendicitis, 48 patients were in $>7.5$ score group $(85.7 \%)$ and 8 were in $<7.5$ score group ( $14.3 \%)$. When analyzed with respect to histopathology the sensitivity of the scoring system in the present study came out to be $100 \%$, specificity of $75 \%$, positive and negative predictive values were $95.83 \%$ and $100 \%$ respectively. Negative appendectomy rate was $4.17 \%$ and accuracy was $88 \%$. Chong, et al. [21] study based on retrospective quoted that the expected sensitivity and specificity of the RIPASA scoring system were $88 \%$ and $67 \%$ respectively, and diagnostic accuracy being $81 \%$. The positive and negative predictive values were expected to be $93 \%$ and $53 \%$ respectively.

On comparing both the scoring systems in our study, RIPASA score has been found more sensitive (100\%) as compared to Alvarado (65\%), Alvarado score was more specific $(100 \%)$ as compared to RIPASA score $(75 \%)$. Positive predictive value of Alvarado score came out to be $100 \%$ as compared to $95.83 \%$ in RIPASA score. Negative predictive value of RIPASA scoring system was $100 \%$ as compared to $33.33 \%$ in Alvarado system. Accuracy of Alvarado system was $83 \%$ as compared to $83 \%$ in RIPASA system. Negative appendectomy rate by application of Alvarado system was zero as compared to $4.17 \%$ by RIPASA system. In a prospective study by the sensitivity, specificity, positive predictive value, negative predictive value and diagnostic accuracy of the RIPASA score were $98 \%, 81.3 \%$, $85.3 \%, 97.4 \%$ and $91.8 \%$ respectively when compared to Alvarado score with sensitivity, specificity, positive predictive value, negative predictive value and diagnostic accuracy of $68.3 \%, 87.9 \%, 86.3 \%$, $71.4 \%$ and $86.5 \%$ respectively.

Receptor operative curve analysis was done in the present study to look for the cut off score for both the scoring systems, with good sensitivity and specificity. Alvarado score cut off was found to be $>7$ while original cut off was $>7.5$ The sensitivity and specificity at score $>7$ was found to be $67.37 \%$ and $80 \%$ respectively, when compared with sensitivity and specificity of $65 \%$ and $80 \%$ respectively at cut off $>7$ in the present study Regar, et al. [16]. RIPASA score cut off came out to be $>7$, which was inconsistent with the original cut off $>7.5$. The sensitivity and specificity were found to be $94.74 \%$ and $60 \%$ respectively at cut off $>7$, which were near sensitivity and specificity of $100 \%$ and $75 \%$ respectively at cut off $>7.5$ as in the present study. The cut off value needs to be evaluated in further studies with increased sample size and in different geographic conditions [16].

\section{Summery}

Appendicitis is a common surgical problem, appendicitis patients were primarily met by resident and junior surgeons, and the 
Citation: Mostafa M. Elhosseiny, Eman Eltokhy, Omar Atef Elekiabi, Mostafa M. Elaidy, Tamer Mohamed El shahidy, et al. Comparative Study between Alvarado Score\& Ripasa Score in Diagnosis of Acute Appendicitis. J Surgery. 2018;6(2): 5.

rate of unnecessary admission is high as well as the rate of negative appendectomy, many clinical scoring systems were developed with the aim of helping diagnosis or exclusion of acute appendicitis, we applied a comparison between ALVARADO and RIPASA scores In this study, and we found that ALVARADO score is more efficient in exclusion of acute appendicitis and Ripasa score is more efficient in diagnosing acute appendicitis.

So, Alvarado score application in the diagnosis of acute appendicitis can reduce negative appendectomy exploration. Application of Alvarado score in diagnosis of acute appendicitis is enough and no need radiological confirmation; however, to be accurate the study should be carried out over larger number of patients.

\section{Conclusion}

The present study has shown that ALVARADO provides fair degrees of sensitivity, specificity, PPV, NPV and accuracy in the diagnosis of acute appendicitis and has found to be more helpful by showing lower negative appendectomy rate, It is therefore recommended that ALVARADO should be used at Emergency unit to improve the diagnostic accuracy of acute appendicitis and subsequently reduce unnecessary admission and negative appendectomy and complication rates.

\section{References}

1. Ohle R, O'Reilly F, O 'Brein KK, Fahey T, Dimitrov BD (2011) The Alvarado score for predicting acute appendicitis: asystematic review. BMC Med 9: 139.

2. Nema P, Kumar AJ (2016) A clinical comparative study of different scoring systems in acute appendicitis. Int Surg J 3: 184-188.

3. Denizbasi A, Unluer EE (2016) The role of the emergency medicine resident using the Alvarado scores in the diagnosis of acute appendicitis compared with the general surgery resident. Eur J Emerg Med 10: 296-301.

4. Lane MJ, Liu DM, Huynh MD, Jeffrey RB Jr, Mindelzun RE, et al. (1999) Suspected acute appendicitis: nonenhanced helical CT in 300 consecutive patients. Radiology 213: 341-346.

5. McGory ML, Zingmond DS, Nanayakkara D, Maggard MA, Ko CY (2005) Negative appendectomy rate: influence of CT scans. Am Surg 10: 803-808.
6. Verma M, Chanchal, Karamveer, Vashist MG, Goyal K, et al. (2015) Comparision of Alvarado And Ripasa Scoring Systems in Diagnosis of Acute Appendicitis 4: 1-3.

7. Alvarado A (2016) How to improve the clinical diagnosis of acute appendicitis in resource limited settings. World J Emerg Surg 11: 16

8. Riaz KM, Kelly ME, Khan W, Waldron1 R, Barry K (2017) Application of Alvrado sore in appendicitis. Ayub Med Coll Abbotta bad 10.

9. Owen TD, William H, Stiff G (2016) Evaluation of Alvrado score in appendicitis. JR Soc Med 85: 86-89.

10. Sand M, Trullen XV, Bechara FG, Pala XF, Sand D, et al. (2015) A prospective bicenter study investigating the diagnostic value of procalcitonin in patients with acute appendicitis. Eur Surg Res 43: 291-297.

11. Wu JY, Cheng SS, Lee SH, Lee CC, Chan RC, et al. (2015) Diagnostic role of procalcitonin in Patients with suspected appendicitis. World J Sur 36: 17441749.

12. Lee SL, Ho Hs, Stiff G (2006) Acute appendicitis: Is there a difference between children and adults ?Am Surg 72: 409-413.

13. Hawkins JD, Thirlby RC (2009) The accuracy and role of cross sectional imaging in diagnosis of acute appendicitism. Adv surg 43: 13-22.

14. Nema P, Jain AK (2016) A clinical comparative study of different scoring systems in acute appndicitis 3.

15. Singh CA, Singh AP, Sajith BS, Gaharwar APS (2016) Role of Alvarado Score in Diagnosis and Management of Acute Appendicitis. Int J Sci Stud 4: $173-177$.

16. Regar MK, Choudhary GS, Nogia C , Pipal DK, Agrawal A (2017) Comparison of Alvarado and RIPASA scoring systems in diagnosis of acute appendicitis and correlation with intraoperative and histo pathological findings. Int Surg J 4: $1755-1761$.

17. Dey S, Mohanta PK, Baruah AK, Kharga B, Bhutia KL, et al. (2010) Alvarado scoring in acute appendicitis a clinicopathological correlation. Indian J Surg 72: $290-293$.

18. Jawaid A, Asad A, Motiei A, Munir A, Bhutto E, et al. (2000) Clinical scoring system: a valuable tool for decision making in cases of acute appendicitis. J Pak Med Assoc 49: 254-259.

19. Baidya N, Rodrigues G, Rao A, Khan SA (2006) Evaluation of Alvarado score in acute appendisitis: a prospective study. Int J Surg 9: 1-3.

20. Chan MY, Teo BS, Ng BL (2001) The Alvarado score and acuteappendicitis. Ann Acad Med Singap 30: 510-514.

21. Chong CF, Adi MI, Thien A, Suyoi A, Mackie AJ, et al. (2011) Development of the RIPASA score: a new appendicitis scoring system for the diagnosis of acute appendicitis. Singapore Med J 51: 220-225. 